\title{
What is the Best Root Surface Treatment for Avulsed Teeth?
}

\author{
Elif B. Tuna ${ }^{1, *}$, Duygu Yaman ${ }^{2}$ and Seiko Yamamato ${ }^{3}$ \\ ${ }^{I}$ DDS, PhD, Department of Pediatric Dentistry, Faculty of Dentistry, Istanbul University, Capa, Istanbul, Turkey \\ ${ }^{2} \mathrm{DDS}$, PhD, Department of Periodontology, Faculty of Dentistry, Istanbul University, Capa, Istanbul, Turkey \\ ${ }^{3} \mathrm{DDS}$, PhD, Department of Pediatric Dentistry, School of Dentistry, Nihon University at Matsudo, Chiba, Japan
}

\begin{abstract}
Dental avulsion is the most severe type of traumatic tooth injuries since it causes damage to several structures and results in avulsion of the tooth from its socket. Management protocols for avulsed teeth should include management of the pulp and periodontal ligament (PDL) cells in order to improve the long-term prognosis and survival of these teeth. The prognosis of the treatment as well as the survival of an avulsed tooth depends on intrinsic and extrinsic factors, such as the duration of the tooth's extra-alveolar period, replantation time, the type of storage medium, PDL status and duration of splinting.

Recent research has led to the development of storage media. However, there is not yet a single solution that fulfills all requirements to be considered as the ideal medium for temporary storage of avulsed teeth, and research on this field should carry on. On the other hand in case of delayed replantation, due to the great risk of tooth loss after avulsion, different root surface treatments have been proposed to prevent and delay root resorption before replantation. For this purpose, researchers have applied some different root surface treatment modalities in delayed replantation of avulsed teeth. Several protocols have been used to maintain PDL viability; some involve fluorides, steroids, sodium alendronate, enamel matrix derivatives (EMD) and basic fibroblast growth factor (bFGF, FGF-2). Among these applications, bFGF shows promising results in the regeneration of natural tooth structures and tissues. Better understanding of mechanism of bFGF may help to improve new technologies of regeneration of tooth structures.
\end{abstract}

Keywords: Avulsion, dental trauma, replantation, root surface treatment, storage media, survival rate.

\section{INTRODUCTION}

Traumatic dental injuries are often seen among injuries to the face. The frequency of the reported incidence of tooth avulsion, which is known as complete displacement of a tooth from its socket, ranges from $1-16 \%$ of all traumatic injuries to permanent dentition [1]. Many of these teeth are knocked-out during daily activities or sporting events especially in contact sports. In cases of avulsion, mechanical trauma to the periodontal ligament (PDL), dehydration, and PDL cell viability particularly can complicate the prognosis [2].

The ideal treatment for an avulsed tooth is its immediate replantation into the socket, which significantly improves the prognosis. In 1706, Pierre Fauchard reported the case of avulsed teeth being replanted [3]. Andreasen reported in a retrospective study that $90 \%$ of avulsed teeth could be successfully retained when they were replanted within the first 30 minutes of the accident in 1966 [4]. Since then the extension possibility of survival rate of replanted teeth has been widely investigated.

*Address correspondence to this author at the Istanbul University Faculty of Dentistry, Department of Pediatric Dentistry, 34093, Capa, Istanbul, Turkey; Tel: +90 2124142020 / 30283; Fax: +90 212531 0515;

Email: ebtuna@istanbul.edu.tr
Although the best therapy for avulsed teeth is their immediate replantation, many factors may affect this approach after trauma. The prognosis of the treatment as well as the survival of an avulsed tooth in the mouth depends on intrinsic and extrinsic factors, such as the duration of the tooth's extra-alveolar period, its storage medium, replantation time, PDL status and duration of splinting [1]. 60 minutes of extraoral dry time is considered to be critical. In order to protect PDL cells and provide optimum healing, immediate replantation is the most ideal treatment among other options. However, clinically, it has been reported that the replantation period was lasting 1-4 hours following the tooth storage in insufficiently wet/dry storage [5]. Dry storage of avulsed teeth leads to death of PDL cells attached to the root. Partial or total lack of PDL leads to ankylosis since the activity of cells derived from the PDL plays a crucial role in the prevention of ankylosis. Therefore, maintaining PDL vitality is crucial for a good prognosis since the presence of necrotic PDL remnants can cause the development of root resorption $[2,6]$. Unfortunately, immediate replantation of the tooth is not always possible in clinical conditions; consequently, delayed replantation is commonly observed [7].

\section{STORAGE MEDIA FOR A VULSED TEETH}

To achieve a more favorable prognosis after replantation, use of a suitable storage medium is a critical factor. The ca- 
pacity of the storage medium to maintain the viability of PDL cells has been considered as more important than the duration of extra-alveolar time [8]. An ideal storage medium is capable of maintaining PDL and pulp cell viability, while presenting clonogenic capacity, antioxidant property, no or minimal microbial contamination, compatible physiological $\mathrm{pH}$ and osmolality, high availability, ready accessibility and low cost $[8,9]$. Blomlof showed the storing of the PDL cells in a biocompatible medium and offered that the best storage medium was a fluid called Hank's Balanced Solution (HBSS) in 1980 [10]. In 1992, Trope and Freidman showed that extracted dog's teeth could be stored in HBSS for up to 96 hours and still maintain significant vitality [11]. In this study, milk was only able to maintain vitality for two hours. Since then and currently HBSS or chilled milk are considered and their use is recommended by the International Association of Dental Traumatology [12] and the American Academy of Pediatric Dentistry [13] since their environments closely resembles the original socket environment. Normally metabolizing tooth root cells have 280-320 $\mathrm{mOs} / \mathrm{kg}$ internal cell pressure (osmolality) and $7.4 \mathrm{pH}$ [11]. In order to maintain this normalcy, the environment in which the teeth are stored must supply the optimum osmolality (cell pressure), cell nutrients and $\mathrm{pH}[10]$.

Since then, many studies have been conducted to determine the storage solutions that allow the maintenance of cell viability in the longest period for avulsed teeth. These storage media include saliva, water, ice, physiologic saline, Viaspan ${ }^{2}$, Minimum Essential Medium (MEM), propolis, green tea extract, red mulberry, egg white, coconut water, sports drink and oral rehydration solutions [14]. Some other types of storage liquids have been tested such as soymilk, powdered milk, Enfamil, and contact lens solution. However, all of them have been shown to either be ineffective or damaging to avulsed teeth in varying stages.

As replantation of avulsed teeth occurs more frequently between 1 and $4 \mathrm{~h}$ after avulsion, degeneration of cemental PDL fibers that embedded into the cementum is a common event and the presence of necrotic PDL remnants on the root surface stimulates the occurrence of inflammatory root resorption, which is the major cause of loss of replanted teeth [15]. When there is an interrupted blood supply, all of the metabolites (calcium, phosphate, potassium) and glucose that the cells require are needed. Studies have shown that teeth that are protected in a physiologically ideal media can be replanted within 15 minutes to one hour after the accident with good prognosis [16]. In case of delayed replantation, in order to increase survival rate of the avulsed tooth some applications have been recommended before replantation.

\section{RECENT DEVELOPMENTS ON ROOT SURFACE MODALITIES IN DELAYED REPLANTATION}

In case of delayed replantation, due to the great risk of tooth loss after avulsion, a variety of adjunctive treatments have been proposed to prevent and delay root resorption before replantation thereby increasing the survival of replanted teeth [17]. Recent research proposed preventing ankylosis by applying to the root surface a medium that favors the regeneration of injured parts of the PDL in delayed replantation of avulsed teeth.

Gulinelli et al., immersed teeth into $2 \%$ acidulated phosphate sodium fluoride and propolis solutions (15\%) following by dry storage for 60 minutes. The authors observed similar external root resorption in the propolis and fluoride groups and did not show differences between the treatment modalities [18]. Selvig et al., applied $0.1 \%$ stannous fluoride followed by $1 \%$ tetracycline and replanted. They found complete absence of inflammatory resorption in $85 \%$ of the root surface area compared to $33 \%$ in control teeth. The authors concluded that the findings indicate that reducing the strength of the stannous fluoride solution from $1 \%$ to $0.1 \%$ may result in less persistent inflammation, at the cost, however, of less complete prevention of inflammatory resorption and ankylosis [19]. When zoledronic acid was used in the root surface treatment of late replanted teeth, studies showed that zoledronic acid was capable of limiting the occurrence of root resorption and preserving cementum resorption. However, the authors suggested that further research should be performed to confirm the use of zoledronic acid in root surface treatment of late replanted teeth [20].

Recently, the use of enamel matrix derivatives (EMDs) in periodontal regeneration was shown to support the role played by cementum in periodontal wound healing. Emdogain $^{\circledR}$ (Biora AB, Malmö, Sweden), a commercialized EMD product, was developed for the regeneration of periodontal tissues. Clinically, EMD has been recommended to stimulate periodontal cells to regain normal periodontal apparatus. Emdogain contains an enamel matrix protein extracted from developing porcine embryonic enamel in a sterilized aqueous solution of propylene glycol alginate [21, 22]. The effect of EMD on periodontal healing and root resorption after tooth replantation has been investigated in many preclinical and clinical studies. However, there are controversies with regard to the regenerative role of EMD in replanted teeth.

Araujo et al., performed a dog study to assess whether EMD applied to the root surface of extracted teeth or teeth that were previously exposed to root planning can protect the tooth from ankylosis following replantation. Following the application, the samples were prepared for histological and morphometric assessments. They observed that healing of a replanted root deprived of vital cementoblasts was characterized by processes that included root resorption, ankylosis and new attachment formation. Furthermore, when an EMD applied to the root surface, an enhanced formation of cementum-either cellular or acellular-with large numbers of inserting collagen fibers occurred [22].

However some other researchers reported that EMD showed a higher incidence of healed PDL. In another dog study, Iqbal and Bamaas assessed the effect of EMD on periodontal healing in teeth replanted after 15, 30 and 60 minutes of 
dry storage. This animal study reported a lower incidence of replacement resorption in dog teeth when EMD was applied to the root surface prior to replantation, compared with teeth not pre-treated before replantation. They showed that EMD significantly decreased replacement root resorption, while it promoted normal periodontal healing. [23].

EMD was shown to promote periodontal healing during replantation in some studies, whereas in other studies EMD did not prevent root resorption. Based on the results of a meta-analysis study conducted by Kim and Ryu, it can be concluded that the treatment of EMD before replantation may be effective in enhancing normal healing and reducing inflammatory and replacement root resorption in the presence of PDL (extraoral time is up to 60 minutes or less). However, in the absence of PDL (extraoral time > $60 \mathrm{~min}-$ utes) no definite conclusion could be drawn with regard to the effect of EMD on periodontal healing and root resorption due to heterogeneity of the included studies [17].

Lately, topical application of basic fibroblast growth factor (bFGF or FGF-2) has been shown to regenerate the natural periodontium in association with the replantation of traumatically avulsed teeth. Cell differentiation is required to produce the necessary supporting structures in cases of tooth transplantation and periodontal regeneration to replace missing tissues and structures, such as PDL and bone [24]. bFGF presents in the ectomesenchyme during the early embryonic stage plays an important role in periodontal regeneration by causing angiogenesis, chemotaxis and the proliferation of undifferentiated ectodermal cells in PDL [25].

Various protocols have been proposed for the prevention of tooth loss due to resorption, ankylosis or inflammation occurring after replantation of an avulsed tooth. In the case of ankylosis, bone and fibrovascular tissue replacement is observed in the area of resorption. Dentin and bone are in direct contact, and extraction of the tooth is generally the only surgical option. Diverse evidence clearly indicates that the local application of recombinant bFGF stimulates bone formation at the applied site, enhances endothelial cell proliferation and diffusion preventing ankylosis [26].

Sritanai et al., evaluated the effect of bFGF on root resorption after delayed auto transplantation in dogs and found replanted teeth following bFGF application yielded formation of new periodontal ligament-like tissues with inserting collagen fibers, associated cementum, and bone. The occurrence of replacement resorption in the bFGF treated group was significantly lower than in the control group. They concluded that topical application of bFGF reduced the occurrence of ankylosis and root resorption after delayed auto transplantation [27]. Furthermore, other researchers reported that the replantation of teeth in monkeys in sockets filled with bFGF, with or without fibrin glue, showed higher occurrence of healing in the bFGF/fibrin glue group. The topical application of bFGF also stimulates multi-potential mesenchymal cells within the PDL, thereby inducing differentiation into-and the subsequent regeneration of - the desired periodontal tissue. They suggested that topical application of
bFGF with fibrin glue showed an insignificantly higher occurrence of complete healing in delayed-replanted monkey teeth [28].

bFGF supports periodontal regeneration by stimulating periodontal ligament cell proliferation and enabling healing. Several studies have shown that bFGF had a stimulating effect on osteoblastic cell proliferation and growth [29]. bFGF plays a role together with other FGFs during dentin and enamel differentiation and proliferation.

The avulsed tooth should be stored in storage media until replanted. Further, conditioning the surface of the tooth with the appropriate agent can increase the chances of functional healing. PDL vitality is the primary factor in the prevention of ankylosis in cases of dental avulsion. For a successful tooth transplantation, cellular vitality and function in the PDL and cementum must be preserved. Katayama et al. have proposed tooth transplantation associated with a proliferating tissue rich in bFGF for the preservation of cellular function and tooth nourishment, thereby preventing ankylosis and root resorption [26]. bFGF enhances endothelial cells proliferation and diffusion and hereby preventing ankylosis.

Tuna et al. recently evaluated the effects of bFGF and EMD on root resorption in dogs' teeth during delayed replantation by histopathologic examination and morphometric assessment. Non-carious and closed apex maxillary incisor and mandibular first premolar teeth were atraumatically extracted to simulate dental avulsion. Extracted teeth were immersed in bovine milk at room temperature for either 45 or $60 \mathrm{~min}$. Following storage, sockets were washed and teeth treated with either $200 \mu \mathrm{g}$ of bFGF (human recombinant bFGF, Wako, Osaka, Japan) diluted with $5 \mathrm{~mL}$ sterile purified water or $0.1 \mathrm{~mL}$ of EMD gel (Emdogain ${ }^{\circledR}$, Straumann, Basel, Switzerland) dispensed from a blunt needle syringe onto the root surface. After extraction, teeth were divided into six groups with three teeth each with different combinations of extra-alveolar periods and treatments. The histopathologic, morphometric assessments and Micro CT (Computerized tomography) examination were made 8 weeks after surgery. The percentage of each histological classification for each root and treatment group was calculated statistically. In this study, the most promising results in all experimental groups occurred in those in which the root surfaces were treated with bFGF. The histopathological differences observed in this study between the storage durations and treatments indicate that the use of bFGF favored the formation of regenerative periodontal tissue in tooth replantation. Besides, the incidence of ankylosis decreased, and most importantly the root was protected from replacement resorption in all specimens of teeth treated. On the other hand, the highest average root resorption occured in the EMD-treated groups in both radiographic and histomorphometric analyses. In this study, treatment with EMD gel did not seem to influence the periodontal healing of the replanted teeth. The application of EMD on the root surface appeared to have limited inductive effect on the remaining PDL cells, although this might change if the local environment on the root surface can be changed [30]. 


\section{CONCLUSION}

The benefit of tooth replantation especially in growing children and adolescents is mainly the time gained to establish an optimal permanent treatment plan, preservation of the width of the alveolar bone contour and contributes to future prosthetic treatment planning. In the worst-case scenario, even if the replanted tooth is extracted later, the improved alveolar development will provide better options for future prosthetic restoration.

Individuals suffering from craniofacial trauma involving tooth avulsion usually receive their first aid treatment in the hospital's emergency service or general practitioner office. Therefore, in most situations, important factors for the success of replantation cannot be controlled. Studies have shown that this scenario can be improved significantly with educational campaigns on dento-alveloar trauma and storage media directed to lay people and non-dental health professionals, especially those working in emergency assistance services [17].

As a treatment option, replantation restores occlusal function and esthetics shortly after injury. In cases of delayed replantation, in order to increase survival rate of the avulsed tooth some applications have been recommended before replantation. Among them basic fibroblastic growth factor (bFGF, FGF-2) shows promising results in the regeneration of natural tooth structures and tissues. A thorough understanding of this molecule in terms of its potential and functions may open up new horizons for medical science and new hopes for patients [31]. Future developments in tissue engineering might facilitate improved periodontal regeneration and may provide a new perspective on the treatment of delayed replanted teeth.

\section{CONFLICT OF INTEREST}

The authors confirm that this article content has no conflict of interest.

\section{ACKNOWLEDGEMENTS}

Declared none.

\section{REFERENCES}

[1] Casaroto AR, Hidalgo MM, Sell AM, et al. Study of the effectiveness of propolis extract as a storage medium for avulsed teeth. Dent Traumatol 2010; 26(4): 323-31

[2] Seshima F, Ota M, Kinumatsu T, Shibukawa Y, Yamada S. Effect of recombinant basic fibroblast growth factor on reimplanted teeth in beagle dogs. Oral Surg Oral Med Oral Pathol Oral Radiol Endod 2010; 109(1): 142-8.

[3] Fauchard P. Le Chirurgien dentist outrait edes'dents. Paris: Chez Pierre-Jean Mariette 1746

[4] Andreasen JO, Hiorting-Hansen-E. Replantation of teeth: I. Radiographic and clinical study of 110 human teeth replanted after accidental loss. Acta Odontol Scand 1966; 24: 263-86.

[5] Panzarini SR, Gulinelli JL, Poi WR, Sonoda CK, Pedrini D, Brandini DA. Treatment of root surface in delayed tooth replantation: a review of literature. Dent Traumatol 2008; 24(3): 277-82.

[6] Ivanovski S, Haase HR, Bartold PM. Isolation and characterization of fibroblasts derived from regenerating human periodontal defects. Arch Oral Biol 2001; 46(8): 679-88.
Andersson L, Bodin I. Avulsed human teeth replanted within 15 minutes-a long-term clinical follow-up study. Endod Dent Traumatol 1990; 6: 37-42.

Gopikrishna V, Baweja PS, Venkateshbabu N, Thomas T, Kandaswamy D. Comparison of coconut water, propolis, HBSS, and milk on PDL cell survival. J Endod 2008; 34: 587-9.

Thomas T, Gopikrishna V, Kandaswamy D. Comparative evaluation of maintenance of cell viability of an experimental transport media "coconut water" with Hank's balanced salt solution and milk, for transportation of an avulsed tooth: an in vitro cell culture study. J Conserv Dent 2008; 11: 22-2.

Blomlof L. Milk and saliva as possible storage media for traumatically exarticulated teeth prior to replantation. Swed Dent J 1981; [suppl 8]: 1-25.

Trope M, Freidman S. Periodontal healing of replanted dog's teeth stored in ViaSpan, milk, Hank's balanced salt solution. Endo Dent Traumatol 1992; 8: 183-8.

Flores MT, Andersson L, Andreasen JO, et al. International Association of Dental Traumatology. Guidelines for the management of traumatic dental injuries. II. Avulsion of permanent teeth. Dent Traumatol 2007; 23: 130-6.

American Academy of Pediatric Dentistry. Available from: http://www.aapd.org/media /Policies_Guidelines/G_trauma.pdf . Accessed date: 12. 02.2014.

Poi WR, Sonoda CK, Martins CM, et al. Storage media for avulsed teeth: a literature review. Braz Dent J 2013; 24(5): 437-45.

Andreasen JO. Effect of extra-alveolar period and storage media upon periodontal and pulp healing after replantation of mature permanent incisors in monkeys. Int J Oral Surg 1981; 10: 43-53.

Andreasen JO. Etiology and pathogenesis of traumatic dental injuries. Scand J Dent Res 1970; 78: 329.

Kim SG, Ryu SI. Enamel matrix derivative for replanted teeth in animal models: a systematic review and meta-analysis. Restor Dent Endod 2013; 38(4): 194-203.

Gulinelli JL, Panzarini SR, Fattah CM, et al. Effect of root surface treatment with propolis and fluoride in delayed tooth replantation in rats. Dent Traumatol 2008; 24(6): 651-7.

Selvig KA, Bjorvatn K, Bogle GC, Wikesjö UM. Effect of stannous fluoride and tetracycline on periodontal repair after delayed tooth replantation in dogs. Scand J Dent Res 1992; 100(4): 200-3

Mori GG, Janjacomo DM, Nunes DC, Castilho LR. Effect of zoledronic acid used in the root surface treatment of late replanted teeth: a study in rats. Braz Dent J 2010; 21(5): 452-7.

Heiji L, Heden G, Svardstrom G, Ostgren A. Enamel matrix derivative (Emdogain) in the treatment of intrabony periodontal defects. J Clin Periodontol 1997; 24: 705-14.

Araújo M, Hayacibara R, Sonohara M, Cardaropoli G, Lindhe J. Effect of enamel matrix proteins (Emdogain') on healing after reimplantation of "periodontally compromised" roots: an experimental study in the dog. J Clin Periodontol 2003; 30(10): 855-61.

Iqbal MK, Bamaas N. Effect of enamel matrix derivative (EMDOGAIN) upon periodontal healing after replantation of permanent incisors in beagle dogs. Dent Traumatol 2001; 17(1): 36-45.

Rifkin DB, Moscatelli D. Recent developments in the cell biology of basic fibroblast growth factor. J Cell Biol 1989; 109: 1-6.

Seshima F, Ota M, Kinumatsu T, Shibukawa Y, Yamada S. Effect of recombinant basic fibroblast growth factor on reimplanted teeth in beagle dogs. Oral Surg Oral Med Oral Pathol Oral Radiol Endod 2010; 109: 142-8.

26] Katayama A, Ota M, Sugito H, Shibukawa Y, Yamada S. Effect of proliferating tissue on transplanted teeth in dogs. Oral Surg Oral Med Oral Pathol Oral Radiol Endod 2006; 101: e110-8.

Shiratani S, Ota M, Fujita T, Seshima F, Yamada S, Saito A. Effect of basic fibroblast growth factor on root resorption after delayed auto transplantation of tooth in dogs. Oral Surg Oral Med Oral Pathol Oral Radiol 2012; 114(2): e14-21.

Sae-Lim V, Ong WY, Li Z, Neo J. The effect of basic fibroblast growth factor on delayed-replanted monkey teeth. J Periodontol 2004; 75(12): 1570-8.

Sugimoto S, Ota M, Shibukava Y, Yamada S. Formation of new periodontal ligament around transplanted teeth with proliferating 
tissue in periodontal osseous defect under barrier membrane. Biomed Res 2004; 25: 179-87.

[30] Tuna EB, Kiyoshi A, Tekkesin MS, et al. Effect of fibroblast growth factor and enamel matrix derivative treatment on priodontal healing mechanism after tooth replantation. [Manuscript accepted].
[31] Sonmez AB, Castelnuovo J. Applications of basic fibroblastic growth factor (FGF-2, bFGF) in dentistry. Dent Traumatol 2013 doi: 10.1111/edt.12071. [Epub ahead of print].

Received: April 10, 2014

Revised: August 07, 2014

Accepted: August 27, 2014

(C) Tuna et al.; Licensee Bentham Open.

This is an open access article licensed under the terms of the Creative Commons Attribution Non-Commercial License (http://creativecommons.org/licenses/by-nc/3.0/) which permits unrestricted, non-commercial use, distribution and reproduction in any medium, provided the work is properly cited. 